Pacific Journal of 


\title{
GENERALISATION OF A “SQUARE” FUNCTIONAL EQUATION
}

\author{
A. K. Gupta
}

Recently the difference equation defining the triangular array of binomial coefficients, known as Pascal's triangle, has been extended to a square functional equation which generates a tableau of numbers. In the present paper these results have been generalised and the generating function for this new set of numbers has been obtained. Several relations among these numbers, which help construct the tableau, are studied. Some further generalisations of these numbers are also given.

1. Introduction. Let $I, I^{+}$and $R$ denote the set of integers, the set of nonnegative integers and the set of real numbers, respectively. The function $f$ defined on the lattice $I^{+} \times I^{+}$which satisfies the difference equation

$$
f(n+1, r)=f(n, r)+f(n, r-1)
$$

and is uniquely determined by initial values on $I^{+} \times\{0\}$ and $\{0\} \times I^{+}$ describes the well known triangular array of numbers. This has been generalised by many authors (see Gupta [4], [5], Cadogan [1], Stanton and Cowan [6]). In [5] Gupta has studied the square functional equation

$$
g(n+1, r+1)=g(n, r+1)+g(n+1, r)+g(n, r)
$$

which together with the boundary conditions $g(n, 0)=g(0, r)=1, \forall n$, $r \in I^{+}$uniquely determines a tableau. However, here we obtain a more general class of functions defined by

$$
g: I^{+} \times I^{+} \longrightarrow R
$$

satisfying the general square functional equation

$$
\begin{aligned}
g(n, r)= & p_{1} g(n-1, r)+p_{2} g(n, r-1) \\
& +p_{3} g(n-1, r-1) p_{i} \in R, \quad i=1,2,3,
\end{aligned}
$$

subject to certain initial conditions $g(n, 0)=p_{1}^{n}$. It may be noted that $g(n, r)$ is not symmetric in $n$ and $r$. Also notice that if $p_{i}=1, i=$ $1,2,3$ this reduces to the case studied earlier (Gupta [5]). In the next section we will give some results for this generalised function $g(n, r)$. However details will be skipped since they are similar to the results in Gupta [5] or Stanton and Cowan [6]. 
2. Properties of $g(n, r)$. Let us define the generating function $A(x, y)$ by

$$
A(x, y)=\sum_{n=0}^{\infty} \sum_{r=0}^{\infty} g(n, r) x^{n} y^{r}
$$

and invoke the recurrence relation (3), along with the initial conditions, we get

$$
\frac{1}{1-p_{2} x-p_{1} y-p_{3} x y}=\sum_{n=0}^{\infty} \sum_{r=0}^{\infty} g(n, r) x^{n} y^{r}
$$

which expresses $A(x, y)$ as a rational function, and may be used to evaluate $g(n, r)$ either explicity or asymptotically. However if we let $g(n, 0)=d, \forall n$ the generating function is given by

$$
A(x, y)=\frac{d\left(1-p_{1} y\right)}{(1-y)\left(1-p_{1} y-p_{2} x-p_{3} x y\right)} .
$$

LEMMA 1. $g(n, r)$ is the coefficient of $x^{n}$ in the expansion of $\left(p_{2}+p_{3} x\right)^{r} /\left(1-p_{1} x\right)^{r+1}$ and is given by

$$
g(n, r)=\left(\frac{p_{3}}{p_{2}}\right)^{n} p_{2}^{r} \sum_{k}\left(\begin{array}{c}
r \\
n-k
\end{array}\right)\left(\begin{array}{c}
r+k \\
k
\end{array}\right)\left(\frac{p_{1} p_{2}}{p_{3}}\right)^{k} .
$$

Proof. Define $A_{r}(x)=\sum_{n=0}^{\infty} g(n, r) x^{n}$. Then it is easy to show, by using (3) and the initial conditions that

$$
A_{r}(x)=\frac{\left(p_{2}+p_{3} x\right)^{r}}{\left(1-p_{1} x\right)^{r+1}}
$$

By expanding the right-hand side of (7) we get the result (6).

Again if we let $g(n, 0)=d$, then $g(n, r)$ is the coefficient of $x^{n}$ in the expansion of

$$
\frac{d}{1-x}\left[\frac{p_{2}+p_{3} x}{1-p_{1} x}\right]^{r}
$$

LEMMA 2. We have,

$$
\begin{aligned}
g(n, r) & =\left(\frac{p_{3}}{p_{2}}\right)^{n} \sum_{\alpha}\left(\begin{array}{c}
n \\
\alpha
\end{array}\right)\left(\begin{array}{c}
r+\alpha \\
n
\end{array}\right)\left(\frac{p_{1} p_{2}}{p_{3}}\right) \alpha, \\
& =\left(\frac{p_{3}}{p_{2}}\right)^{n} \sum_{\beta}\left(\begin{array}{l}
r \\
\beta
\end{array}\right)\left(\begin{array}{l}
n \\
\beta
\end{array}\right)\left(1+\frac{p_{1} p_{2}}{p_{3}}\right)^{\beta} .
\end{aligned}
$$

Proof. Similar to the proof of Lemma 2 of [6].

LEMMA 3. If $d_{m}=\sum_{n+r-m}^{\infty} g(n, r)$, then 
(9)

$$
d_{m+2}=\left(p_{1}+p_{2}\right) d_{m+1}+p_{3} d_{m} .
$$

If we let $p_{i}=1, i=1,2,3$ we get Lemma 4 of [6].

The following relation can easily be verified and corresponds to Lemma 3 of [5].

$$
g(n, r+s)=\sum_{k} g(k, r)\left[g(n-k, s)-p_{1} g(n-k-1, s)\right] .
$$

The relationship of $g(n, r)$ with the hypergeometric function ${ }_{2} F_{1}$ is given by

$$
g(n, r)=\left(\frac{p_{3}}{p_{2}}\right)_{2}^{n} F_{1}\left(-n, r ; 1 ; 1+\frac{p_{1} p_{2}}{p_{3}}\right) .
$$

This Gauss hypergeometric series reduces to a polynomial of degree $n(r)$ in $\left(1+\left(p_{1} p_{2} / p_{3}\right)\right)$ for $n(r)=0,1,2, \cdots$. From this relation (11) we can derive many results, of which we give only one below.

$$
\begin{aligned}
g(n, r)= & \frac{1}{n}\left[(n-1) \frac{p_{1} p_{2}}{p_{3}} g(n-2, r)\right. \\
& \left.-\left\{(n-1-r)\left(1+\frac{p_{1} p_{2}}{p_{3}}\right)-2 n+1\right\} g(n-1, r)\right] .
\end{aligned}
$$

This relation corresponds to Lemma 5 of [5] and is useful in computing the numbers $g(n, r)$. Results corresponding Lemma 6 of [5] and many more can be similarly obtained.

3. Further generalisation. In general $g(n, 0)=d_{n} \in R$. In $\S 2$ we have treated the special case when $d_{n}=p_{1}^{n}$. In fact different initial conditions give rise to (i) an Arithmetic progression and (ii) Geometric progression for the numbers $g(n, 0)$. However in general we can prove the following.

THEOREm 1. We have,

$$
g(n, r)=\sum_{\substack{u, v, w \\
u+v+w=r}}\left(\begin{array}{c}
r \\
u, v, w
\end{array}\right) p_{1}^{u} p_{2}^{v} p_{3}^{w} g(n-r+v, u)
$$

where

$$
\left(\begin{array}{c}
r \\
u, v, w
\end{array}\right)=\frac{r !}{u ! v ! w !}
$$

With initial conditions explicit formulae can be obtained.

We can further generalise by considering 


$$
g: I \times I \times I^{+} \longrightarrow R
$$

where

$$
\begin{aligned}
g(n, m, r)= & p_{1} g(n, m, r-1)+p_{2} g(n, m-1, r-1) \\
& +p_{3} g(n-1, m-1, r-1) .
\end{aligned}
$$

Then $g(n, m, r)$ satisfies the following theorem, (see [1]).

THEOREM 2. We have

$$
g(n, m, r)-\sum_{\substack{u, v, w \\
u+v+w=r}}\left(\begin{array}{c}
r \\
u, v, w
\end{array}\right) p_{1}^{u} p_{2}^{v} p_{3}^{w} g(n-w, m-v-w, 0) .
$$

Many generalisations are possible by increasing the dimension of the lattice, and/or by redefining the functional equation that gives the recurrence relation.

4. REMaRK. Earlier in [2] and [3] the value of $g(n, r)$ found its applications in sphere packing, coding metrics and chess puzzles. Since the present function is a generalisation of this earlier result, it is hoped that these numbers too will be of use in such context.

\section{REFERENCES}

1. Charles Cadogan, Some generalisations of the Pascal triangle, Math. Mag., 45 (1972), 158-162.

2. S. W. Golomb, Sphere Packing, Coding Metrics, and Chese Puzzless, Proceedings of the Second Cahpel Hill Conference on Combinatorial Mathematics and its Applications, University of North Carolina (1970), 176-189.

3. S. W. Golomb and L. R. Welch, Algebraic Coding and the Lie Metric, Error Correcting Codes, (edited by H. B. Mann), John Wiley and Sons, Inc., New York, 1968, 175-194.

4. A. K. Gupta, On Pascal's triangle of the third kind, Biom. Z., 15 (1973), 389-392.

5. - On a 'square' functional equation, Pacific J. Math., 50 (1974), 447-454.

6. R. G. Stanton and D. D. Cowan, Note on a 'square' functional equation, SIAM Review, 12 (1970), 277-279.

Received August 26, 1974.

The University of Michigan 


\section{PACIFIC JOURNAL OF MATHEMATICS}

\section{EDITORS}

RICHARD ARENS (Managing Editor)

University of California

Los Angeles, California 90024

\section{J. DugundJI}

Department of Mathematics University of Southern California Los Angeles, California 90007

D. Gilbarg and J. Milgram

Stanford University

Stanford, California 94305
University of Washington Seattle, Washington 98105

\section{ASSOCIATE EDITORS}
E. F. BECKENBACH
B. H. NeumanN
F. WolF
K. YoShIDA

\section{SUPPORTING INSTITUTIONS}

\author{
UNIVERSITY OF SOUTHERN CALIFORNIA \\ STANFORD UNIVERSITY \\ UNIVERSITY OF TOKYO \\ UNIVERSITY OF UTAH \\ WASHINGTON STATE UNIVERSITY \\ UNIVERSITY OF WASHINGTON \\ $\stackrel{*}{*} \stackrel{*}{*} \stackrel{*}{ }{ }^{*}$ AMERICAN MATHEMATICAL SOCIETY
}

The Supporting Institutions listed above contribute to the cost of publication of this Journal, but they are not owners or publishers and have no responsibility for its content or policies.

Mathematical papers intended for publication in the Pacific Journal of Mathematics should be in typed form or offset-reproduced, (not dittoed), double spaced with large margins. Underline Greek letters in red, German in green, and script in blue. The first paragraph or two must be capable of being used separately as a synopsis of the entire paper. Items of the bibliography should not be cited there unless absolutely necessary, in which case they must be identified by author and Journal, rather than by item number. Manuscripts, in triplicate, may be sent to any one of the editors. Please classify according to the scheme of Math. Reviews, Index to Vol. 39. All other communications should be addressed to the managing editor, or Elaine Barth, University of California, Los Angeles, California, 90024.

The Pacific Journal of Mathematics expects the author's institution to pay page charges, and reserves the right to delay publication for nonpayment of charges in case of financial emergency.

100 reprints are provided free for each article, only if page charges have been substantially paid. Additional copies may be obtained at cost in multiples of 50 .

The Pacific Journal of Mathematics is issued monthly as of January 1966. Regular subscription rate: $\$ 72.00$ a year (6 Vols., 12 issues). Special rate: $\$ 36.00$ a year to individual members of supporting institutions.

Subscriptions, orders for back numbers, and changes of address should be sent to Pacific Journal of Mathematics, 103 Highland Boulevard, Berkeley, California, 94708.

\section{PUBLISHED BY PACIFIC JOURNAL OF MATHEMATICS, A NON-PROFIT CORPORATION}

Printed at Kokusai Bunken Insatsusha (International Academic Printing Co., Ltd.), 270, 3-chome Totsuka-cho, Shinjuku-ku, Tokyo 160, Japan.

\section{Copyright (C) 1975 by Pacific Journal of Mathematics} Manufactured and first issued in Japan 


\section{Pacific Journal of Mathematics}

\section{Vol. 57, No. $2 \quad$ February, 1975}

Norman Larrabee Alling, On Cauchy's theorem for real algebraic curves with boundary .......

Daniel D. Anderson, A remark on the lattice of ideals of a Prüfer domain ..................

Dennis Neal Barr and Peter D. Miletta, A necessary and sufficient condition for uniqueness of

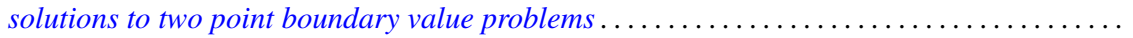

Ladislav Beran, On solvability of generalized orthomodular lattices . . . . . . . . . . ........

L. Carlitz, A three-term relation for some sums related to Dedekind sums . . . . . . . . . .....

Arthur Herbert Copeland, Jr. and Albert Oscar Shar, Images and pre-images of localization

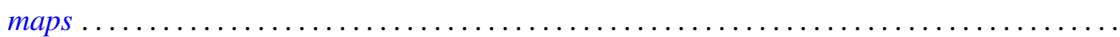

G. G. Dandapat, John L. Hunsucker and Carl Pomerance, Some new results on odd perfect

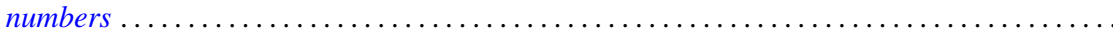

M. Edelstein and L. Keener, Characterizations of infinite-dimensional and nonreflexive

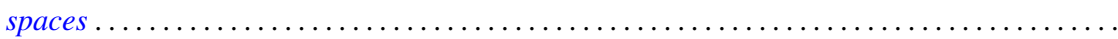

Francis James Flanigan, On Levi factors of derivation algebras and the radical embedding

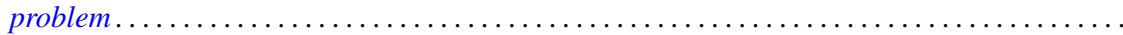

Harvey Friedman, Provable equality in primitive recursive arithmetic with and without

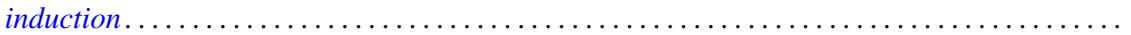

Joseph Braucher Fugate and Lee K. Mohler, The fixed point property for tree-like continua with

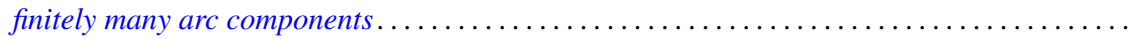

John Norman Ginsburg and Victor Harold Saks, Some applications of ultrafilters in

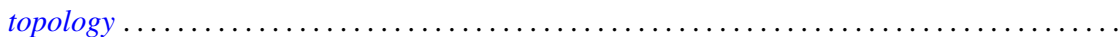

Arjun K. Gupta, Generalisation of a "square" functional equation .....................

Thomas Lee Hayden and Frank Jones Massey, Nonlinear holomorphic semigroups ..........

V. Kannan and Thekkedath Thrivikraman, Lattices of Hausdorff compactifications of a locally

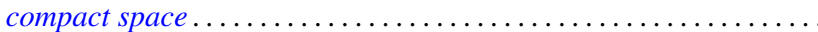

J. E. Kerlin and Wilfred Dennis Pepe, Norm decreasing homomorphisms between group

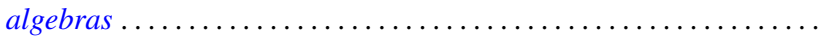

Young K. Kwon, Behavior of $\Phi$-bounded harmonic functions at the Wiener boundary ...

Richard Arthur Levaro, Projective quasi-coherent sheaves of modules .

Chung Lin, Rearranging Fourier transforms on groups...........................

David Lowell Lovelady, An asymptotic analysis of an odd order linear differential equation . . 4475

Jerry Malzan, On groups with a single involution .......................... 481

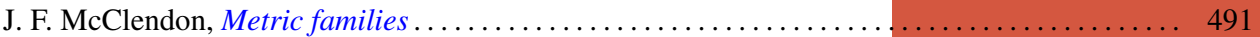

Carl Pomerance, On multiply perfect numbers with a special property .

Mohan S. Putcha and Adil Mohamed Yaqub, Polynomial constraints for finiteness of semisimple rings. .

Calvin R. Putnam, Hyponormal contractions and strong power convergence . . . . . . . . . 531

Douglas Conner Ravenel, Multiplicative operations in $\mathrm{BP} * \mathrm{BP} \ldots \ldots \ldots \ldots \ldots \ldots \ldots \ldots \ldots .539$

Judith Roitman, Attaining the spread at cardinals which are not strong limits . . . . . . . . . 545

Kazuyuki Saitô, Groups of *-automorphisms and invariant maps of von Neumann algebras . . . 553

Brian Kirkwood Schmidt, Homotopy invariance of contravariant functors acting on smooth

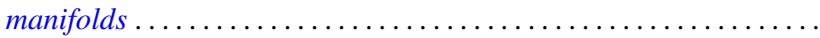

Kenneth Barry Stolarsky, The sum of the distances to $N$ points on a sphere.

Mark Lawrence Teply, Semiprime rings with the singular splitting property.

J. Pelham Thomas, Maximal connected Hausdorff spaces..............

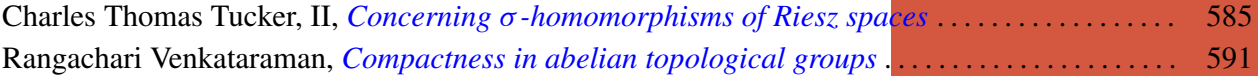

William Charles Waterhouse, Basically bounded functors and flat sheaves . . . . . . . . . . . 597

David Westreich, Bifurcation of operator equations with unbounded linearized part ......... 611

William Robin Zame, Extendibility, boundedness and sequential convergence in spaces of 